\title{
RESTABELECIMENTO ("RECOVERY") EM PLANTAS DE FUMO ATACADAS PELO VIRUS DE "VIRA-CABEÇA"
}

\author{
R. Forster
}

\section{INTRODUÇÃO}

Dos vários fatos observados em plantas atacadas por moléstias causadas por virus, um há em que a planta apresenta, após a primeira manifestação de sintomas, nova formação de ramos laterais ou mesmo principal, isentos de sintomas. Estes, todavia, continuam visiveis nas partes já anteriormente atacadas, sem que haja, porem, novo progresso. Quando isso acontece em consequência do desaparecimento do virus dos tecidos da planta, dá-se a esta particularidade a denominação de "recovery" (12) ou, diríamos, restabelecimento da planta. Deve-se distinguir, do que ficou dito, o mascaramento de sintomas em plantas infecionadas por virus, pois, neste caso, o virus continua a existir nos tecidos da planta, tratando-se, portanto, de plantas somente portadoras de virus, em geral resistentes aos seus efeitos prejudiciais.

No trabalho que passaremos a relatar, pretendemos apresentar uma nova interpretação para o problema do "recovery" e que merecel nossa atenção, por três razões: a) poderia a reação da planta ao virus, produzindo o "recovery", indicar uma maior resistência constitucional do indivíduo em comparação às suas plantas irmãs tambem atacadas pelo virus e que não apresentaram "recovery" ; b) poderia tratar-se de imunidade fisiológica adquirida ; c) ou tratar-se-ia de um fato acidental condicionado pelo ambiente.

Baseamos nossas observações em plantas de fumo atacadas pelo "vira-cabeça" e que apresentaram "recovery", isto é, restabeleceramse e chegaram a produzir sementes (6).

Se se verificasse a primeira hipótese teríamos um caminho aberto para a tentativa de obtenção de linhagens de fumo resistentes ao virus do "vira-cabeça", e constituiria isso uma solução para o problema de 
defesa contra a moléstia. Foi visando esclarecer este ponto de vista que realizamos o presente trabalho. Quanto à segunda hipótese não representava a finalidade de nosso trabalho pelo que a resumimos em pequenas observações em campo e citação de trabalhos publicados. A terceira hipótese significa uma exclusão das duas primeiras e que tornaria o assunto sem importância.

Casos de "recovery" em plantas atacadas por moléstias de virus já foram encontrados sob diversas condições, para diversas plantas e moléstias. Assim, encontramos em Smith (12) citação de diversos casos de "recovery", completos ou parciais. Limitamos nossas referências aos que se relacionam com "recovery" de "vira-cabeça" em fumo. Smith (11) trata de casos de "recovery" em plantas de fumo atacadas pelo "tomato spotted wilt" com produção de ramos livres de virus e tambem de alguns casos de "recovery" completo em plantas de fumo. Moore (10) refere-se tambem a casos de "recovery" parcial ou completo de "kromnek" em fumo. Plantas "recovery" de "vira-cabeça" foram observadas por Forster e Costa (6). Em nenhum desses trabalhos, porem, o assunto foi discutido sob o ponto de vista que nos interessa presentemente, como acima referido. Posteriormente, prosseguimos observando sempre o aparecimento de novas plantas "recovery" ao lado das que já havíamos colhido $(7,8)$.

\section{"VIRA-CABEÇA" EM FUMO}

Entre as moléstias de fumo, causadas por virus, que ocorrem nas culturas dessa planta, encontra-se a denominada "vira-cabeça" (6), que se identifica com o "spotted wilt", com o "kromnek" e outras estudadas sob vários nomes (3).

Como sintomas mais gerais encontrados em plantas de fumo afetadas pelo "vira-cabeça", podemos citar: torção no broto terminal, que dá origem ao nome da moléstia; paralização do crescimento, lesões necróticas ao longo da haste principal e nos brotos. Nas folhas há rugosidade do limbo, clorose das nervuras, mais tarde segue-se necrose, que com o tempo se generaliza na planta toda; algumas folhas, especialmente as novas, sofrem torção lateral ou para baixo como consequência de desigualdade de crescimento na folha, após a infeção do virus ; posteriormente, há um murchamento generalizado da planta, sintoma esse visivel, às vezes, logo na fase inicial.

O ataque do "vira-cabeça" é mais frequente e acentuado de acordo com certas condições, entre outras, dependendo das variedades, das 
quais são mais suscetiveis as do tipo amarelo de estufa; idade das plantas, quarto mais rovas mais sujeitas estão à infeção do virus de "vira-cabeça". $O$ aparecimento do "recovery" em plantas atacadas pelo "vira-cabeça" é mais comum em variedades mais resistentes à moléstia, e mais frequentemente observado se a infeção do "vira-cabeça" se processar quando a planta ainda nova, o que se explica pola pequena probabilidade de infeção do virus em plantas adultas.

\section{ASPECTO GERAL DO "RECOVERY" OU RESTABELECIMENTO}

A planta afetada pelo "vira-cabeça" em via de regra sucumbe, sendo pequena a percentagem das que apresentam "recovery". Este pode ser observado em ramos laterais após a infeção da moléstia, mas, em geral, se processe na haste principal (fig. 1).

Una planta restabelecida se apresenta, quando examinada de baixo para cima, corn algumas folhas sadias; em seguida, as que apresentam sintomas de "vira-cabeça" variando estas em rúmero conforme a altura em que a planta manifestou aparecimerito dos primeiros sinais de restabelecimento; depois, folhas que mostram diminuição dos sintomas da moléstia, apresentando-se, então, pequenas, recurvadas, quer lateralmente, quer no sentido da nervura principal; seguem-se folhas com contrações da nervura principal, com o consequente enrugamento do limbo: há depois um desaparecimento gradual dos sintomas em ceral, até que surgem folhas completamente sadias, de tamanho em geral menor do que se se tratasse duma planta sadia. A inflorescência é sempre menor que a de uma planta sadia da mesma variedade (fio. 2). O florescimento da planta restabelecida se processa prematuramente em relação às plantas sadias da mesma idade, o que torna comum encontrarem-se, numa linha, plantas restabelecidas, de pequena altura, já em pleno florescimento, ao lado de plantas sacias mais desenvolvidas e não florescendo ainda (fig. 3); fatos aliás já citacios por Moore (10). A altura das plantas restabelecidas é variavel, dependendo da iciade em que se processou a infeção da moléstia e da reação de restabelecimento da própria planta (figs. 2, 3).

\section{REINFEÇÃO EM PLANTAS "RECOVERY"}

Em alguns casos foi possivel observar que plantas no campo afetadas pelo "vira-cabeça", apresentando "recovery", foram novamente infecionadas pela mesma moléstia, reagindo, porem, uma segunda vez 
com um novo "recovery". Numa tal planta, observando-a de baixo para cima, encontramos sucessivamente algumas folhas sadias, folhas com sintomas de "vira-cabeça", folhas apresentando restabelecimento, folhas sadias, folhas com novos sintomas de "vira-cabeça", novo restabele. cimento e, finalmente, a inflorescência (fig. 4). Na səgunda infeção, em geral os sintomas se marifestam com menor virulência. Costa (4) conseguiu inocular artificialmente o virus de "vira-cabeça" em plantas que apresentavam restabelecimento do "vira-cabeça". Diante disso deve-se, portanto, admitir que o virus de "vira-cabeça" não provoca imunidade, no mínimo completa, na planta de fumo, o que tambem é dito por Smith (11), que tambem reinfecionou artificialmente plantas "recovery" de "spotted wilt" com o virus causador da moléstia. No caso em questão se trata de desaparecimento do virus de "vira-cabeça" dos tecidos da planta, portanto, um verdadeiro "recovery".

\section{OBTENÇÄO DE RESISTENACIA AO "VIRA-CABEÇA" ATRAVÉS DE PLANTAS "RECOVERY"}

Foi nossa intenção saber se a manifestação de restabelecimento das plantas atácadas pelo "vira-cabeça" podia ou não ser interpretada como reação de resistência, visto que relativamente poucas eram as plantas atacadas que se restabeleciam e estas, em geral, pertencentes em maior percentagem às variedades menos suscetiveis ao virus de "vira-cabeça". Para isso, estabelecemos um ensaio de seleção, contrastando sempre as progênies provindas da autofecundação de plantas "recovery" com as que provinham de plantas não "recovery".

As primeiras observações datam de 1937, quando autofecundamos a colhemos sementes de plantas restabelecidas, em número de sete, pertencentes às seguintes variedades: Creoula (V-67, número na coleção); Creoula (V-172), Foga (V-72) e Flor Branca (V-76). No ano seguinte colhemos, nas mesmas condições, mais onze plantas da variedade Ambalema (V-147) que se tem portado relativamente resistente ao "viracabeça" nos ensaios realizados (1). Todas as sementes assim colhidas foram semeadas separadamente, em forma de progênies, procedendo. se nelas à observação do grau de infeção de "vira-cabeça", e do aparecimento de novas plantas "recovery", as quais eram sempre autofecundadas. Para o ensaio final possuíamos, portanto, progênies que procediam de uma a quatro gerações sucessivas de plantas "recovery" autofecurdadas. Em outros casos, após urna ou mais autofecundaçc̃es em gerações seguidas de plantas "recovery", eram ais progênies mantidas a pârtir 
desse momento, pela autofecundação de plantas sadias. Estabelecíamos dessa maneira, o efeito de vários graus acumulados de "recovery", se imaginarmos que esse restabelecimento pudesse representar uma manif́estação de resistência da planta.

Para os ensaios realizados em 1940-4l (quadros I e IV) possuíamos progênies procedentes de uma a três gerações seguidas "recovery". Nesse ano realizamos duas plantações em datas diferentes, isto é, a primeira a 13 de janeiro de 1941 e a segunda a 15 de abril. Para $1941-42$ possuíamos uma geração mais, portanto, progênies que representavam de uma a quatro gerações contínuas de "recovery". Realizamos duas plantações idênticas nas Estações Experimentais de Campinas e Piracicaba. Na Estação Experimental de Tupí, foi feita tambem uma plantação com outro grupo de progênies procedentes de uma geração "recovery". Procuramos para todos os ensaios ter sempre no conjunto de variedades às quais pertenciam as progênies, algumas relativamente resistentes e outras suscetiveís ao "vira-cabeça". Desta maneira, tínhamos mais um elemento de confronto no ensaio final, ao lado de diferentes localidades e graus de "recovery", este como elemento principal na comparação.

\section{ANÁLISE DAS PERCENTAGENS DE INFEÇÃO E RESULTADOS}

Os dados de infeção de "vira-cabeça" expressos em percentagem, foram submetidos a cálculos estatísticos. As percentagens obtidas para 1940-41, de duas plantações em épocas diferentes, em Campinas, estão contidas no quadro I. Para 1941-42, os dados das plantações de Campinas e Piracicaba estão no quadro II e os da Estação de Tupí estão contidos no quadro III. Baseiam-se essas percentagens em canteiros de 30 plantas para 1940-41; de 33 plantas para os ensaios de 1941 -42 em Campinas e Piracicaba e de 14 plantas para o ensaio de Tupí. Esses números, representando o "stand" para cálculo, são variaveis, pois sempre descontamos as falhas, de modo que no cálculo os valores porcento usados como variaveis, apresentam o defeito de se basearem nos números totais acima, um pouco divergentes e, assim, consequentemente cada determinação é feita com certa aproximação. Há tambem a considerar o fato de nem todas as variedades possuirem progênies que derivassem de idênticos números de "recovery" contínuos, em consequência do que o número de progênies representando um certo "recovery" não é o mesmo para cada variedade. Então a exatidão na determinação das médias para cada variedade ou "recovery" não é idêntica para todas variedades. 
Pode isso dar a impressão, às vezes, de que houve efeito do "recovery", porem, se isto aconteceu, foi mais tendente a acréscimo na infeção.

Submetemos as percentagens a uma análise "entre-dentro", e os resultados estão contidos nos quadros IV a VI, correspondentes aos dados dos quadros I a III. Fizemos essa análise com certa relutância devido aos fatos acima expostos, porem pensamos que mesmo assim o resultado justifica o procedimento.

Separamos, na decomposição, o erro entre as duas médias que correspondem a lugares diferentes em 1941.42 e às duas épocas para 1940-41, e que correspondem aos efeitos da variação do ambiente sobre a intensidade da infeção, o que poderíamos chamar de variação fenotípica. Como segunda componente destacamos a variação entre as médias para variedades, que, por sua vez, nos dão uma indicação das diferenças constitucionais ou genotípicas entre as mesmas. Em terceiro lugar, figura a componente que se refere à variação entre as diferentes progênies apresentando um ou mais "recovery" em geraçc̃es seguidas. A compo. nente restante consideramos como erro experimental inevitavel.

Em se tratando de variaveis porcento, podíamos pensar que a variação delas quando de acaso e não sistemática devia corresponder a uma variação de distribuição binomial de modo que podemos comparar o erro residual obtido com o erro ideal calculado pela fórmula:

$\tau= \pm \sqrt{\mathrm{p} \%(100-\mathrm{p} \%)}$ em que $\mathrm{p} \%$ representa a percentagem n

rédia de infeção do ensaio e n o número de plantas usado no "stand" de cálculo, para cada ensaio. Comparando esses valores achamos:

\begin{tabular}{|c|c|c|c|c|c|c|}
\hline $\begin{array}{c}\text { ESTACOES } \\
\text { EXPERIMENTAIS }\end{array}$ & $\begin{array}{c}\text { Ano } \\
\text { agrícola }\end{array}$ & $\begin{array}{l}\text { Erro } \\
\text { residual }\end{array}$ & $\begin{array}{l}\text { Graus de } \\
\text { liberdade }\end{array}$ & $\begin{array}{l}\text { Erro } \\
\text { ideal }\end{array}$ & $\begin{array}{l}\text { Graus de } \\
\text { liberdade }\end{array}$ & 0 \\
\hline Campinas & $1940-41$ & $\pm 5,44$ & 12 & $\pm 7,65$ & $\infty$ & $0,7 i$ \\
\hline Piracicaba e Campinas & 1941.42 & $\pm 12,37$ & 21 & $\pm 8,35$ & $\infty$ & 1,48 \\
\hline Tupí & 1941.42 & $\pm 17,89$ & 30 & $\pm 13,22$ & $\infty$ & 1,35 \\
\hline
\end{tabular}

Desprezando o caso duvidoso de um erro residual menor que o erro iáeal, ficamos com dois casos em que o erro residual é significante. mente maior que o correspondente ideal. Podemos, pois, bem imaginar que as infeções fortes havidas não decendam só de acaso, mas que podem. 
existir fatores sistemáticos que afetam a infeção, como focos, etc., e que podem ser a causa de erros residuais grandes.

Das três componentes entre mostram-se maiores aquelas que correspondem à variação do ambiente, seja como lugar, seja entre épocas que são até três vezes maiores que o residual.

Tambem há certa variação entre variedades; num caso houve significância, o que, aliás, já conhecemos de outros ensaios $(1,2,9)$.

A terceira componente, que corresponde ao número de "recovery" em gerações seguidas é significante só em um caso (quadro IV). Estudando-se, porem, os valores porcento correspondentes (quadro I) nota-se que as percentagens crescem com o aumento do número de "recovery", isto é, se houve influência da seleção de plantas "recovery" ela foi negativa.

Na Estação Experimental de Tupí plantamos em 1941-42 um lote de 40 progênies pertencentes em igual número a cinco variedades diversas: De cada oito progênies dentro da mesma variedade, cinco se originavam de plantas "recovery" e três de plantas sadias, do ano anterior. Possuíamos assim para análise dois grupos representados pelas progênies "recovery" e pelas não "recovery" com um grau de liberdade; cinco variedades com quatro graus de liberdade; interação grupo-variedade com quatro graus de liberdade e o resíduo com trinta graus de liberdade. Encontramos significância entre variedades para esses valores (quadro VI), sendo que para os grupos "recovery" comparados aos não "recovery" houve insignificância. Temos um total de 40 canteiros e a variação que corresponde aos 30 graus de liberdade restantes, depois de eliminada a variação entre grupos "recovery", entre variedades e a interação, pode ser considerada como erro residual. Como para os outros ensaios, calculamos tambem para este o erro ideal pela fórmula dada, para um número médio de 14 plantas por canteiro, e comparando-o com o erro residual encontramos significância.

\section{CONCLUSÃO}

Comparando os valores que obtivemos nos diversos ensaios, notamos que em um caso somente (quadro IV) obtivemos significância para efeito de "recovery". Examinando, porem, as percentagens correspondentes (quadro I) vemos que as médias de plantas doentes crescem com o aumento do número de gerações "recovery". $\bigcirc$ efeito, se consideravel, é antes de carater negativo quanto à obtenção de resistência através de plantas "recovery". O maior erro é o das plantações, mostrando, assim, maior 
efeito fenotípico do que genotípico. No quadro $\mathrm{V}$ temos como maior erro o das localidades, o único significante em relação ao residual. Novamente predominância de fatores do ambiente e não do acúmulo de "recovery". Os valores do quadro $V$ correspondem a uma geração a mais que os do quadro IV, fator esse que vem ainda uma vez contrabalançar o resultado aparente do quadro IV. No quadro VI encontramos significância somente para diferenças entre variedades, fato aliás já conhecido. Tambem nesse caso não houve efeito de "recovery".

Em conclusão, não é possivel obter resistência por seleção das plantas manifestando "recovery" da infeção de "vira-cabeça", como uma solução para defesa contra esta moléstia. $O$ efeito maior encontrado nesses ensaios, de localidades, de épocas de transplante e até certo limite de variedades, reforçado por resultados de outros ensaios já anteriormente realizados $(1,2,5,9)$ continua a evidenciar o ponto de vista da escolha de regiões para plantações de fumo, onde a média de infeção da moléstia seja mais baixa ou nula e o conhecimento exato das épocas de transplante, nas quais a incidência da moléstia seja mínima, como as melhores medidas atualmente recomendaveis na profilaxia da moléstia de fumo denominada "vira-cabeça".

A plantação, do ensaio na Estação Experimental de Tupí foi executada pelo chefe da Estação sr. Argemiro Frota. As dos ensaios instalados em Campinas, pelo sr. A. Rodrigues Lima, chefe da Seç̧ão de Fumo. O cálculo estatístico foi executado com a orientação do prof. F. G. Brieger, da Escola Superior de Agricultura "Luiz de Queiroz", que tambem apresentou interessantes sugestões para a confecção do texto. A todos registamos aquí os nossos agradecimentos.

\section{S U M M A R Y}

Observations were made with tobacco plants which, after being naturally infected in the field by the virus of "vira-cabeça", a disease identical to spotted wilt (3), not only resisted to it, but exhibited complete recovery. Several trials were carried out in order to ascertain the following points:

1) whether the recovery means a greater degree of individual constitutional resistance ;

2) whether it represents an acquired immunity or ;

3) whether it is just of pure accidental nature.

Plants showing recovery were selfed and seeds collected from them sown in separate rows. The same procedure was always applied with the new recovered plants. Thus, strains of plants were obtained representing several succeeding generations of recovered plants. 
In 1940-41 recovery progenies were planted at two different transplanting periods.

During the next season 1941-42 these progenies, which represented already one more generation in comparison with those of 1940.41, were planted in two districts where the average occurrence of "vira-cabeça" was different.

The percentages of "vira-cabeça", observed in all trials, were submitted to statistical analysis, comparing the errors obtained for difference of districts, transplanting time, varieties and progenies representing several generations of recovered plants.

Comparing the calculated errors it was found that the greatest effect in the occurrence of "vira-cabeça" observed should be attributed to different transplanting times or different districts. The selection of recovered plants showed no influence in lowering the incidence of "vira-cabeça": hence the impossibility of getting types of tobacco resistant to "vira. cabeça" through selection of recovered plants.

Plants were observed in the field that after the first recovery exhibited symptoms of the disease, and then completely recovered from it again. This is in accordance with the results of Smith (11) in the reinoculation of tobacco plants after recovery from spotted wilt and of Costa (4) who reinoculated "vira-cabeça" - recovered tobacco plants with it.

Therefore, as far as our knowledge is concerned districts should be selected where the disease does not appear very frequently; transplanting periods should be chosen, ic guarantee the lowest possible incidence of the disease.

\section{LITERATURA CITADA}

1. Brieger, F. G., A. R. Lima, R. Forster, A. S. Costa e S. Ribeiro dos Santos. Ensaio de épocas de transplante para o fumo. Bragantia 2: 295-312. Quadros I.VIII. 1942.

2. Brieger, F. G., A. R. Lima e R. Forster. Comportamento de variedades e progênies de fumo na resistência ao "vira-cabeça". Bragantia 2: 275-294. 1942.

3. Costa, A. S. e R. Forster. Identidade do virus de "vira-cabeça" e sua inclusão no grupo do virus do "spotted wilt". Bragantia 1:491-516. fig. 1-19. 1941.

4. Costa, A. S. Ensaios diversos com o virus de "vira-cabeça". (Não publicado).

5. Costa, A. S., R. Forster, A. R. Lima e S. R. dos Santos. Contribuição para o conhecimento da distribuição geográfica das moléstias de fumo no Estado de São Paulo. Rev. Agric. Piracicaba 17:237-256. Quadros 1-20. 1942.

б. Forster, R. e A. S. Costa. Nota preliminar sobre a moléstia "vira-cabeça" do fumo. Rev. Agric. Piracicaba 13:69-78. fig. 1-12. 1938.

7. Forster, R. Observações sobre "recovery" de "vira-cabeça" em fumo. Lim Relatório da Seç̧ão de Genética do Instituto Agronômico, 1938-39. (Não publicado).

8. Forster, R. Observações sobre "recovery" de "vira-cabeça" em fumo. Em Relatório da Seç̧ão de Genética do Instituto Agronômico, 1939-40. (Não publicado).

9. Lima, A. R. e A. S. Costa. Variedades de fumo resistentes ao "vira-cabeça". Rev. Agric. Piracicaba 15:133-140. Fig. 1. 1940.

10. Moore, E. S. The Kromnek or Kat River Disease of Tobacco and Tcmato in the East Province (South Africa). Sc. Bull N. ${ }^{\circ}$ 123:1-28. Plat. I-VIII. 1933.

11. Smith, K. M. Studies on potato virus diseases. VIII. On a ring-spot virus affecting Solanaceous plants. Ann. Appl. Biol. 18:1-15, fig. 1-15. 1931.

12. Smith, K. M. Em Recent Advances in the Study of Plant Viruses. pág. 1-423. J. e A. Churchill. London 1933. 


\section{Q U A D R O I}

INFEÇĀO MÉDIA PORCENTO DE "VIRA-CABEÇA" NAS PROGÊNIES DE FUMO DAS PLANTAÇŌES DE 1940-41, NA ESTAÇÃO EXPERIMENTAL DE CAMPINAS, AGRUPADAS POR VARIEDADES E NÚMERO DE GERAÇÖES "RECOVERY"

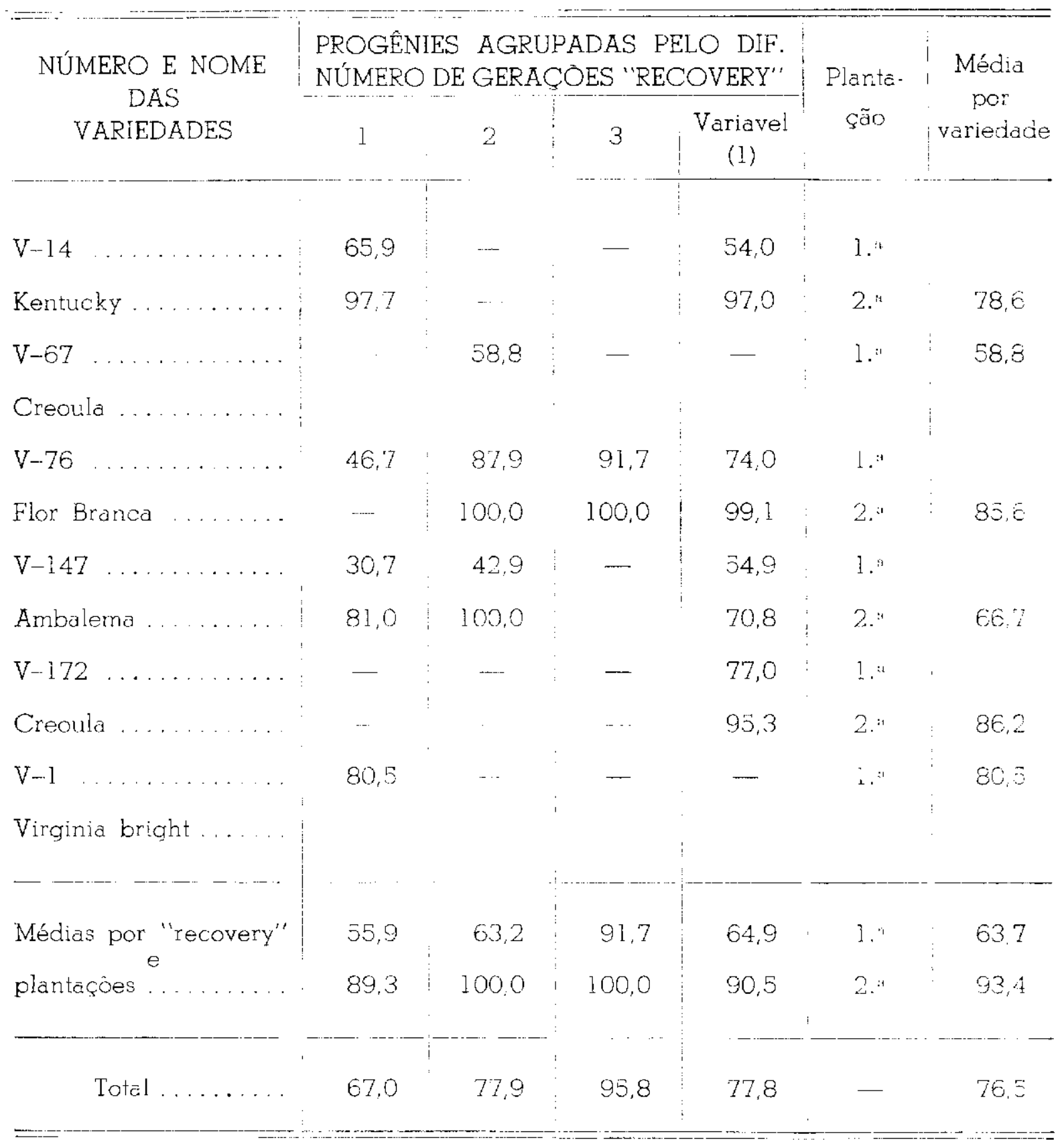

(1) Número variavel de "recovery" sequido de autofecundação em plantas sãs. 


\section{Q U A D R O I I}

INFEÇAO MÉDIA PORCENTO DE "VIRA-CABEÇA" NAS PROGÊNIES DE FUMO NAS PLANTAÇOES DE 1941.42, NAS ESTAÇŌES EXPERIMENTAIS DE CAMPINAS E PIRACICABA, AGRUPADAS POR VARIEDADES E NÚMERO DE GERAÇŌES "RECOVERY"

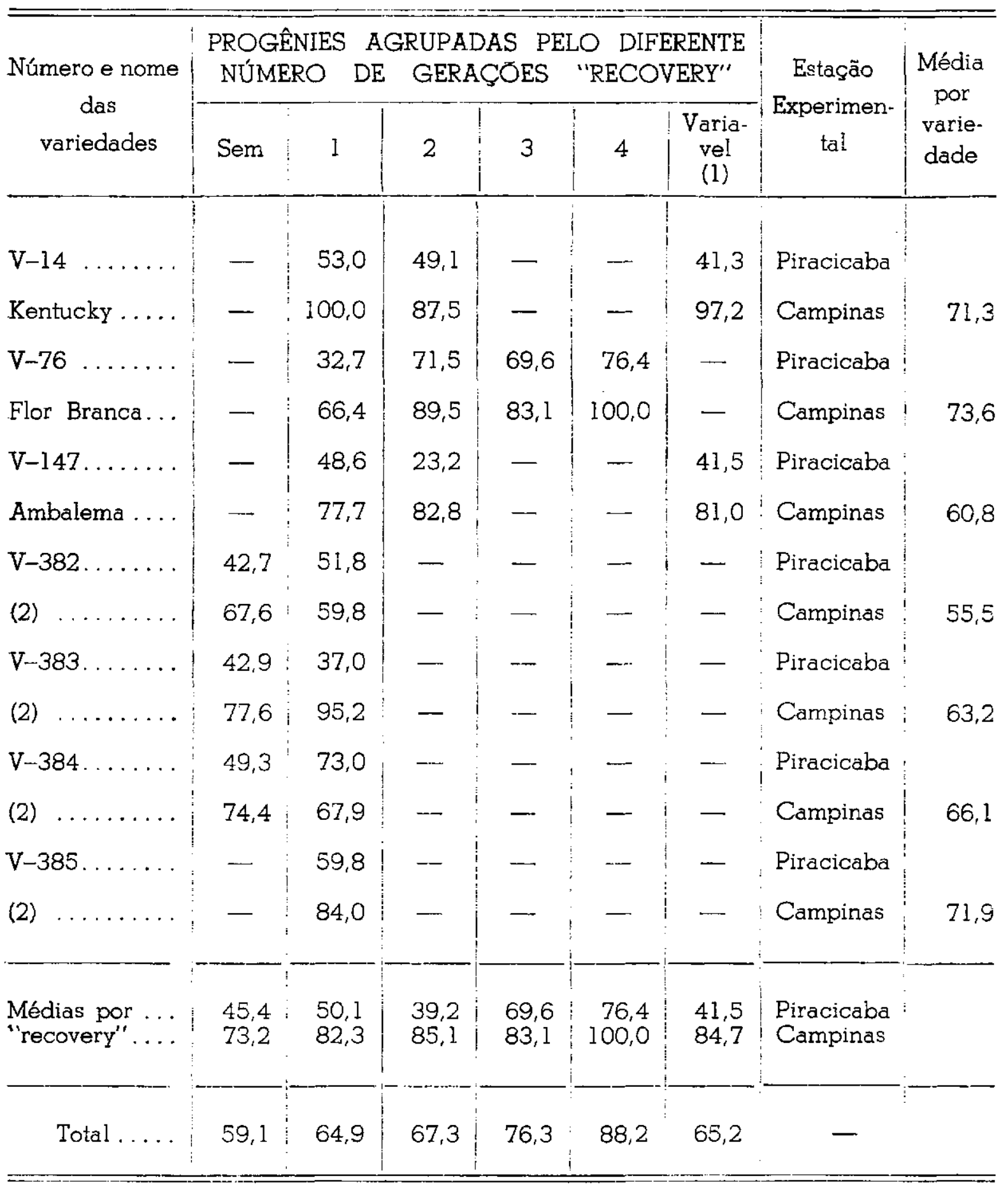

(1) Número variavel de gerações "recovery" seguido de autofecundação em plantaミ sadias.

(2) Linhagens importadas da Colômbia. 


\section{Q U A D R O I I I}

PROGÊNIES DA ESTAÇÃO EXPERIMENTAL DE TUPÍ, EM 1941-42. AS PROGÊNIES MARCADAS COM RC DERIVAM DE PLANTAS "RECOVERY"

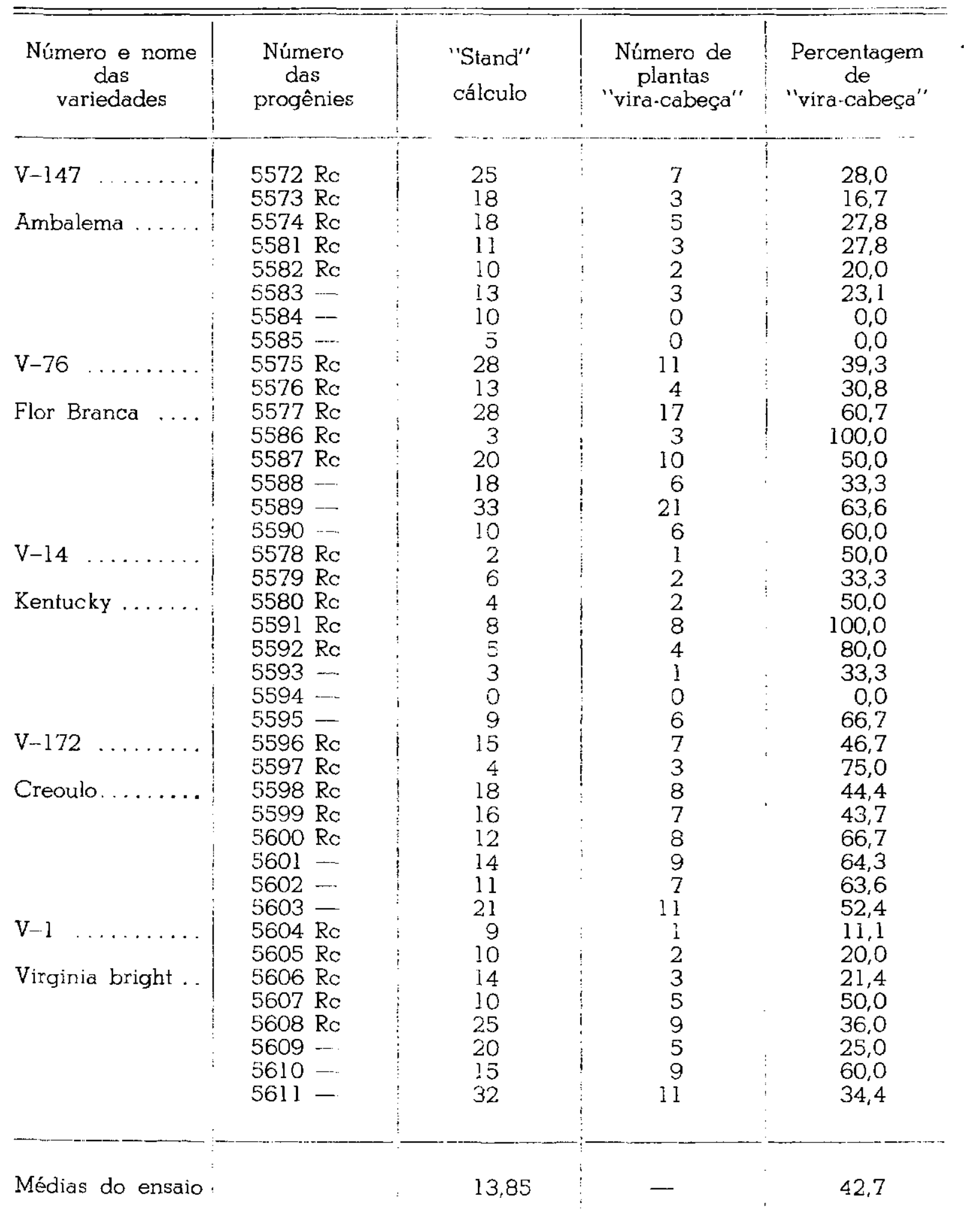




\section{Q U A D R O I V}

DECOMPOSIÇĀO DO ERRO NA ANALLISE DAS PERCENTAGENS DE INFEÇĀO DE "VIRA.CABEÇA" DADAS NO QUADRO I

\section{COMPONENTES}

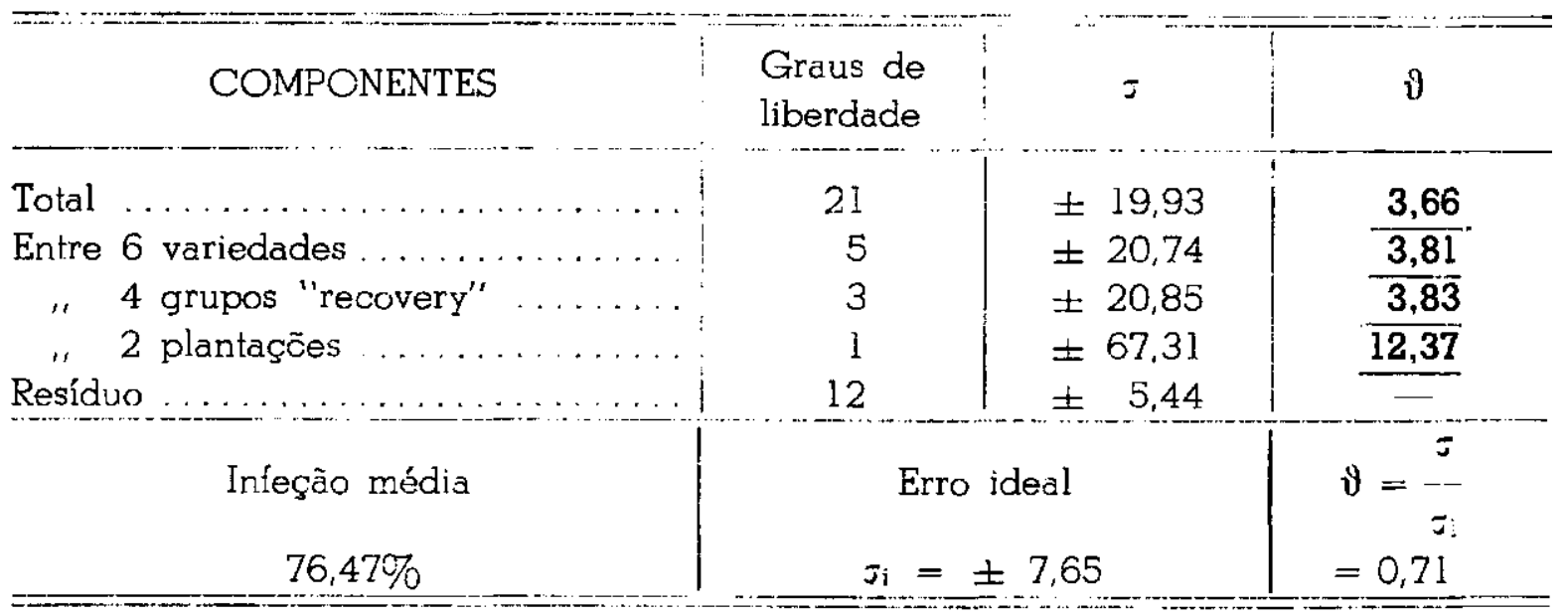

Graus de liberdade

\section{Q U A D R O V}

DECOMPOSIÇĂO DO ERRO NA ANÁLISE DAS PERCENTAGENS DE INFEÇĀO DE "VIRA-CABEÇA" DADAS NO QUADRO II

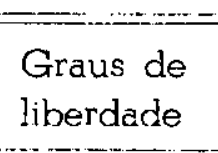

Total

Entre 6 grupos "recovery"

¿2 localidades

" 7 variedacies

Resíduo

Infeção média

$66,30 \%$

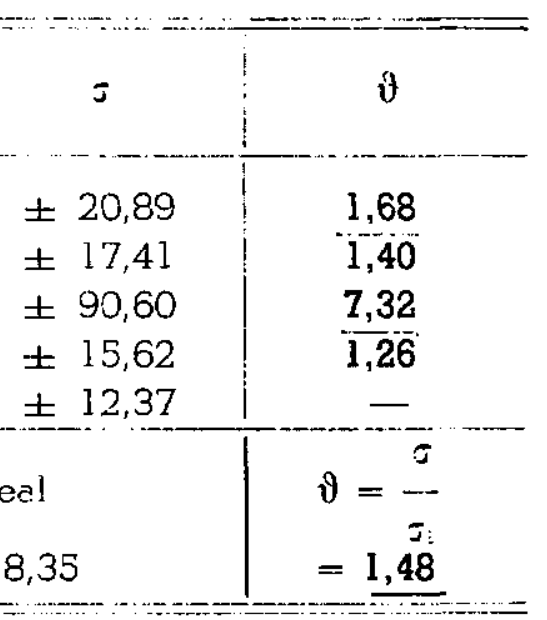

\section{Q U A D R O VI}

DECOMPOSIÇÃO DO ERRO NA ANÁLISE DAS PERCENTAGENS DE INFEÇĀO DE "VIRA-CABEÇA" DADAS NO QUADRO III

\section{COMPONENTES}

Graus de liberdade
Total

Entre 2 grupos

5 variedádes

Interação grupos $\mathrm{x}$ variedades

Resíduo

39
1
4
4
30

$$
\begin{aligned}
& \pm 24,56 \\
& \pm 19,96 \\
& \pm 48,13 \\
& \pm 32,62 \\
& \pm 17,89
\end{aligned}
$$

\section{Erro ideal}

$\tau:= \pm 13.22$
1,38

1,12

2,69

$\overline{1,82}$

Infeção média

$42,70 \%$ 


\section{EXPLICAÇÃO DAS FIGURAS}

Fig. 1. Planta de fumo da variedade Flor Branca (V-76) apresentando "recovery" após a infeção do "vira-cabeça".

Fig. 2. Planta de fumo da variedade Creoula (V-67) apresentando "recovery" de "viracabeça" já florescendo, ao lâdo de planta normai da mesma variedade. Ambas as plantas teem a mesma idade.

Fig. 3. Plantas de fumo da variedade Creoula (V-172) apresentando "recovery" de "vira-cabeça", ao lado de planta normal da mesma variedade. Plantas da. mesma idade.

Fig. 4. Folhas de uma planta de fumo apresentando "recovery" de "vira-cabeça": a) folha sadia; b) folhas com sintomas de "vira-cabeça"; c) folhas da fase "recovery"; d) folhas sadias; e) folhas mostrando reinfeção com imediato "recovery"; f) folhas sadias; g) inflorescência. 


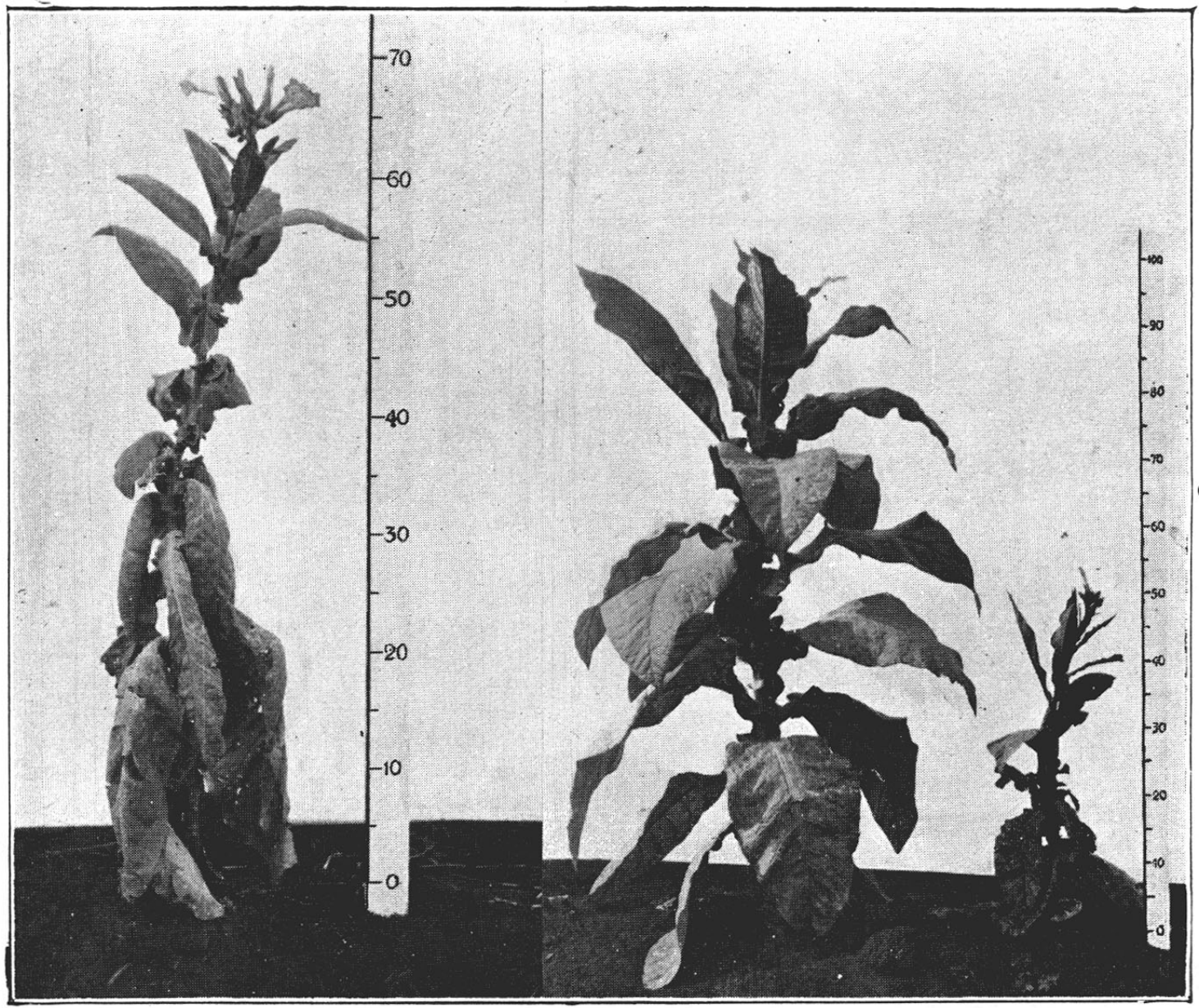

Fiq. 1

Fig. 2

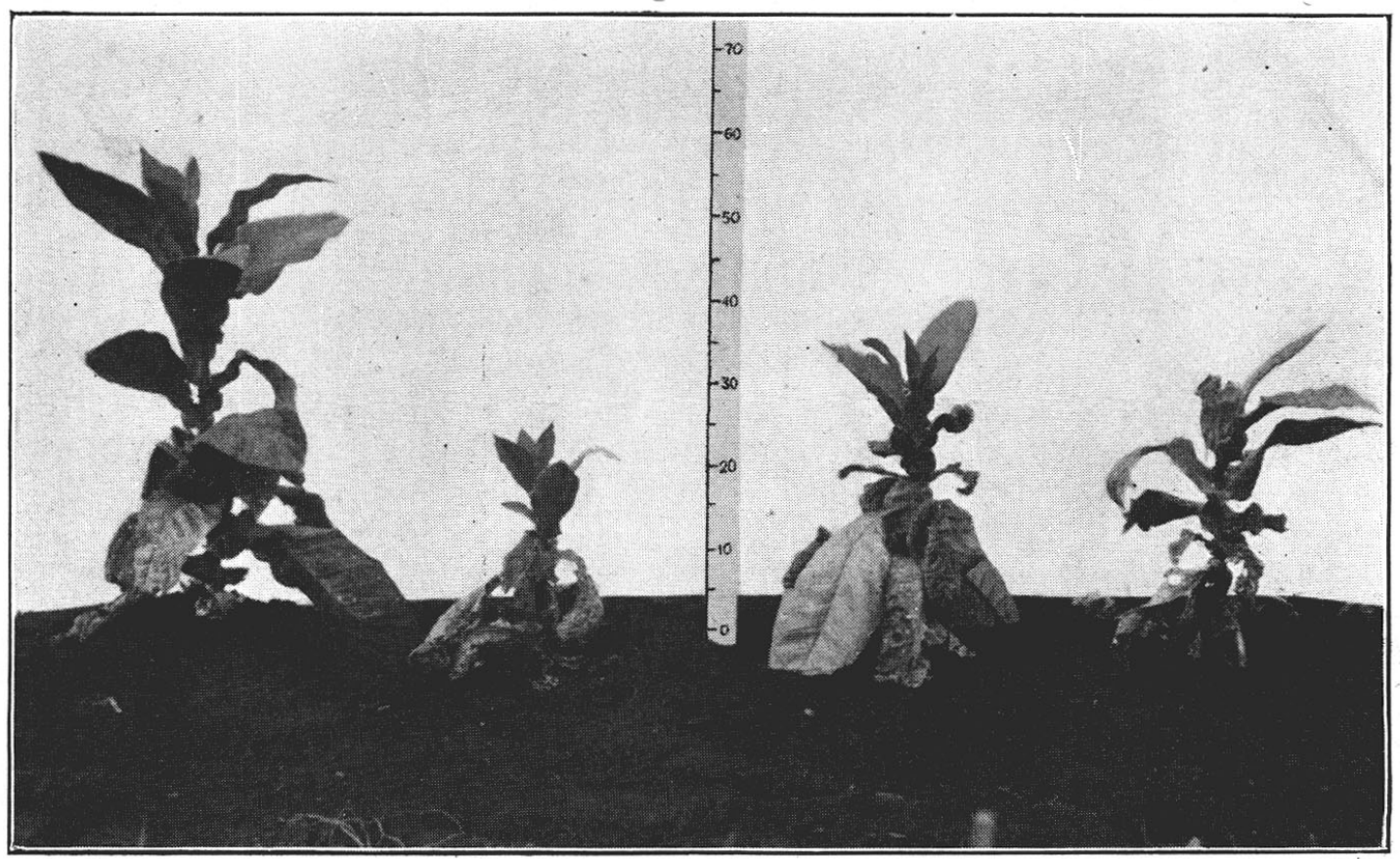

Fig. 3 


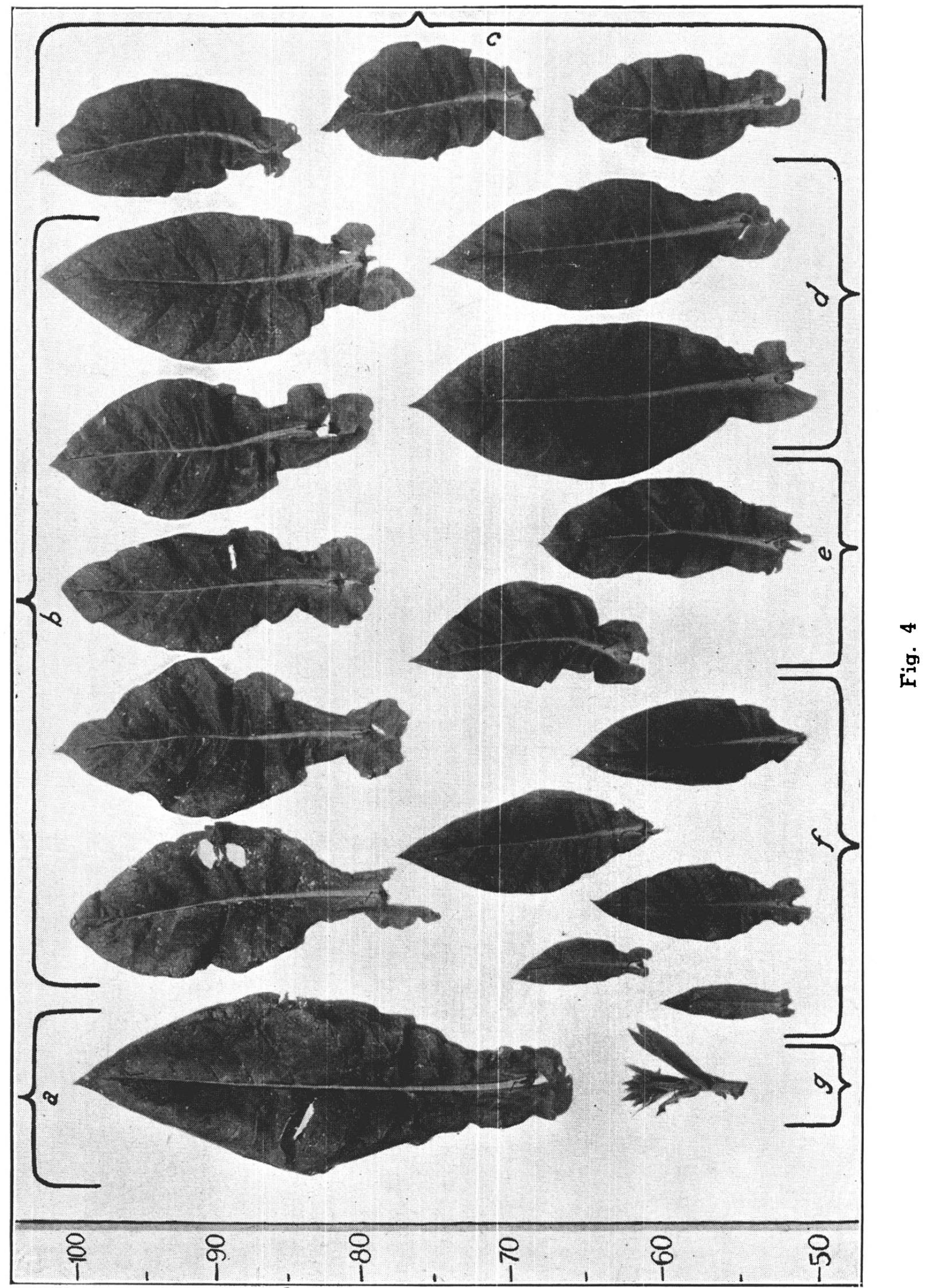

